\title{
Modeled source apportionment of black carbon particles coated with a light-scattering shell
}

\author{
Aki Virkkula \\ Atmospheric Composition Research, Finnish Meteorological Institute, Helsinki, Finland \\ Correspondence: Aki Virkkula (aki.virkkula@fmi.fi)
}

Received: 2 November 2020 - Discussion started: 3 November 2020

Revised: 20 March 2021 - Accepted: 6 April 2021 - Published: 21 May 2021

\begin{abstract}
The Aethalometer model has been used widely for estimating the contributions of fossil fuel emissions and biomass burning to equivalent black carbon (eBC). The calculation is based on measured absorption Ångström exponents $\left(\alpha_{\mathrm{abs}}\right)$. The interpretation of $\alpha_{\mathrm{abs}}$ is ambiguous since it is well known that it not only depends on the dominant absorber but also on the size and internal structure of the particles, core size, and shell thickness. In this work the uncertainties of the Aethalometer-model-derived apparent fractions of absorption by eBC from fossil fuel and biomass burning are evaluated with a core-shell Mie model. Biomass-burning fractions $(\mathrm{BB}(\%))$ were calculated for pure and coated single $\mathrm{BC}$ particles for lognormal unimodal and bimodal size distributions of $\mathrm{BC}$ cores coated with ammonium sulfate, a scattering-only material. $\mathrm{BB}(\%)$ was very seldom $0 \%$ even though $\mathrm{BC}$ was the only absorbing material in the simulations. The shape of size distribution plays an important role. Narrow size distributions result in higher $\alpha_{\mathrm{abs}}$ and $\mathrm{BB}(\%)$ values than wide size distributions. The sensitivity of $\alpha_{\mathrm{abs}}$ and $\mathrm{BB}(\%)$ to variations in shell volume fractions is the highest for accumulation-mode particles. This is important because that is where the largest aerosol mass is. For the interpretation of absorption Ångström exponents it would be very good to measure $\mathrm{BC}$ size distributions and shell thicknesses together with the wavelength dependency of absorption.
\end{abstract}

\section{Introduction}

Incomplete combustion of organic fuels results in emission of light-absorbing carbon (LAC) particles that contain both black carbon (BC) and brown carbon $(\mathrm{BrC})$. $\mathrm{BrC}$ is lightabsorbing organic matter in atmospheric aerosols of various origins, e.g., soil humics, humic-like substances (HULIS), tarry materials from combustion, and bioaerosols (Andreae and Gelenscer, 2006; Laskin et al., 2015). BrC can significantly absorb solar radiation in the ultraviolet-visible (UVVis) wavelength range $(\lambda \approx 300-800 \mathrm{~nm})$. The radiative effects of $\mathrm{BC}$ and $\mathrm{BrC}$ vary in time during atmospheric aging. For many combustion sources the absorbance in fresh emission is almost completely caused by BC particles, but during atmospheric transport they often get coated with some light-scattering compounds, for instance ammonium sulfate or light-absorbing organic carbon, BrC. For some sources (e.g., biomass burning) $\mathrm{BrC}$ may contribute substantially to light absorption already in the directly emitted aerosols and either increase or decrease during aging. Thus, $\mathrm{BrC}$ is highly time-dependent as its composition and absorption properties change during atmospheric oxidation processes (Laskin et al., 2015).

The absorption coefficient $\sigma_{\mathrm{ap}}$ is approximately proportional to the power function $\lambda^{-\alpha_{a b s}}$, where $\lambda$ is the wavelength and $\alpha_{\mathrm{abs}}$ is the absorption Ångström exponent. $\alpha_{\mathrm{abs}}$ is generally used to distinguish aerosol types: for pure BC particles $\alpha_{\text {abs }} \approx 1$, while for other light-absorbing aerosols ( $\mathrm{BrC}$, soil dust) it is clearly $>1$ (e.g., Kirchstetter et al., 2004; Bond and Bergstrom, 2006; Bergstrom et al., 2007; Moosmüller et al., 2011; Kirchstetter and Thatcher, 2012; Lack et al., 2012; Bond et al., 2013; Saleh et al., 2013; Laskin et al., 2015; Valenzuela et al., 2015; Devi et al., 2016). The method has been used not only for in situ absorption measurements but also for interpreting absorption coefficients retrieved from remote sensing measurements, such as the Aerosol Robotic Network (AERONET; e.g., Russell et al., 2010; Arola et al., 2011; Chung et al., 2012; Cazorla et al., 2013; Feng et al., 2013; Schuster et al., 2016; Wang et al., 2016). 
One of the instruments used for measuring black carbon concentrations is the Aethalometer that collects aerosol on a filter tape, measures changes in light attenuation in the wavelength range of $370-950 \mathrm{~nm}$, and calculates the equivalent black carbon (eBC) concentrations. The data are used also to calculate $\alpha_{\text {abs }}$ and to estimate the contributions of fossil fuel emissions and biomass burning to eBC. The Aethalometer model (Sandradewi et al., 2008a) is probably the most widely used method for this, and it is even calculated automatically in the new Aethalometer model AE33. It is there assumed that the absorption Angström exponents are $\alpha_{\mathrm{ff}}=1$ and $\alpha_{\mathrm{bb}}=2$ for eBC from fossil fuel and biomass burning, respectively. These are the default settings in the AE33, but also different $\alpha_{\mathrm{ff}}$ and $\alpha_{\mathrm{bb}}$ values have been used (Sandradewi et al., 2008b; Herich et al., 2011; Fuller et al., 2014; Harrison et al., 2013; Healy et al., 2017; Zotter et al., 2017; Helin et al., 2018)

The interpretation of $\alpha_{\mathrm{abs}}$ is ambiguous since it not only depends on the dominant absorber but also on the size and internal structure of the particles, core size, and shell thickness. For instance, for pure BC particles, $\alpha_{\mathrm{abs}}$ may be $<1$ and BC particles coated with non-absorbing material may have $\alpha_{\mathrm{abs}}$ in the range from $<1$ to $\sim 1.7$ (e.g., Gyawali et al., 2009; Lack and Cappa, 2010; Lack and Langridge, 2013; Schuster et al., 2016; Liu et al., 2018; Chylek et al., 2019; Zhang et al., 2020). The present paper may be considered an extension to the abovementioned analyses since they did not explicitly analyze the effects on the Aethalometer model.

The aim of this study is to estimate uncertainties of the Aethalometer-model-derived fractions of absorption by eBC from fossil fuel and biomass burning when spherical $\mathrm{BC}$ cores are coated by some non-absorbing material. To state this more clearly, it is assumed that there is only one type of BC particles that can be called fossil fuel BC in the Aethalometer model terminology. Consequently, any deviations from biomass-burning fraction of $\mathrm{BB} \%=0$ indicate uncertainty in the source appointment. Biomass-burning fractions were calculated for pure and coated single particles for lognormal unimodal and bimodal size distributions. The work is based on modeling only; no measurement data are used.

\section{Methods}

The BC cores were assumed to be coated with an ammonium sulfate shell by using two approaches. It was assumed (1) that the shell thickness is the same for all particles in a size distribution (Fig. 1a) and (2) that the core volume fraction is the same for all particles in a size distribution (Fig. 1b). The core volume fraction was calculated from

$f_{\mathrm{c}}=\frac{V_{\text {core }}}{V_{\mathrm{p}}}=\left(\frac{D_{\text {core }}}{D_{\mathrm{p}}}\right)^{3}=\left(\frac{D_{\text {core }}}{D_{\text {core }}+2 s}\right)^{3}$, where $V_{\mathrm{p}}$ is the particle volume, $V_{\text {core }}$ is the $\mathrm{BC}$ core volume, $D_{\mathrm{p}}$ is the particle diameter $\left(=D_{\text {core }}+2 s\right), D_{\text {core }}$ is the BC core diameter, and $s$ is the shell thickness. The shell volume fraction was then calculated from $f_{\mathrm{s}}=1-f_{\mathrm{c}}$. The ratio of the coated particle diameter to the core diameter is an often used metric for presenting the coating of particles. $R, f_{\mathrm{c}}$, and $f_{\mathrm{s}}$ can be calculated from each other as

$R=\frac{D_{\mathrm{p}}}{D_{\text {core }}}=\left(\frac{1}{f_{\mathrm{c}}}\right)^{1 / 3}=\left(\frac{1}{1-f_{\mathrm{s}}}\right)^{1 / 3}$.

The number-weighted $D_{\mathrm{p}}$-to- $D_{\text {core }}$ ratio is calculated from

$R_{N\left(D_{\mathrm{p}}\right)}=\frac{\sum N_{i} R_{i}}{N_{\mathrm{tot}}}=\frac{\sum N_{i}\left(D_{\mathrm{p}, i} / D_{\mathrm{core}, \mathrm{i}}\right)}{N_{\mathrm{tot}}}$,

where $N_{i}$ and $R_{i}$ are the number concentration and $D_{\mathrm{p}}$-to$D_{\text {core }}$ ratio of the particle diameter $D_{\mathrm{p}, i}$, respectively. If $f_{\mathrm{s}}$ is independent of particle size - which is the assumption used in some of the simulations below - Eq. (3) simplifies to $R_{N\left(D_{\mathrm{p}}\right)}=R$.

Lognormal size distributions $n\left(D_{\mathrm{p}}, D_{\mathrm{g}}, \sigma_{\mathrm{g}}\right)$ were generated, where $D_{\mathrm{p}}$ is the particle diameter, $D_{\mathrm{g}}$ is the geometric mean diameter, and $\sigma_{\mathrm{g}}$ is the geometric standard deviation. The $D_{\mathrm{p}}$ range was $3 \mathrm{~nm}-10 \mu \mathrm{m}$. For the unimodal size distributions the $D_{\mathrm{g}}$ range was $50 \mathrm{~nm}-1 \mu \mathrm{m}$, and $\sigma_{\mathrm{g}}$ was given three values: 1.4, 1.6, and 1.8 (Fig. 1c and d). Bimodal size distributions were also generated. For the smallparticle mode the geometric mean diameter $D_{\mathrm{g} 1}$ range was $50-100 \mathrm{~nm}$, and the large-particle mode $D_{\mathrm{g} 2}$ range was 100 $500 \mathrm{~nm}$. In addition to varying the geometric mean diameters, the ratios of the number of particles in the two modes were also varied. Two cases were used for this: (1) $N_{1}=10 N_{2}$, $\sigma_{\mathrm{g} 1}=1.4, \sigma_{\mathrm{g} 2}=1.6$ (Fig. 1e) and (2) $N_{1}=N_{2}, \sigma_{\mathrm{g} 1}=1.6$, $\sigma_{\mathrm{g} 2}=1.6$ (Fig. 1f).

Absorption coefficients were calculated from

$\sigma_{\text {ap }}(\lambda)=\int Q_{\mathrm{a}}\left(\lambda, D_{\mathrm{p}}, m_{\text {core }}, m_{\text {shell }}, s\right) \frac{\pi}{4} D_{\mathrm{p}}^{2} n\left(D_{\mathrm{p}}\right) \mathrm{d} D_{\mathrm{p}}$,

where $Q_{\mathrm{a}}$ is the absorption efficiency that is a function of the wavelength $\lambda, D_{\mathrm{p}}$, the complex refractive indices of the core and shell, $m_{\text {core }}$ and $m_{\text {shell }}$, respectively, and the shell thickness $s . Q_{\text {a }}$ was calculated using the N-Mie Fortran code written and described in detail by Voshchinnikov and Mathis (1999). The code is based on the recursive algorithm of $\mathrm{Wu}$ and Wang (1991). The code calculates the extinction, scattering, and absorption efficiency factors for $n$-layered spheres. The complex refractive indices were $m_{\text {core }}=1.85+0.71 i$ (BC as in Lack and Cappa, 2010) and $m_{\text {shell }}=1.52+0 i$ (ammonium sulfate) for the core and shell, respectively. Absorption coefficients were calculated for the Aethalometer wavelengths $\lambda=470$ and $950 \mathrm{~nm}$, and $\alpha_{\text {abs }}$ was calculated from

$\alpha_{\mathrm{abs}}(470 / 950)=-\frac{\ln \left(\sigma_{\mathrm{ap}}(\lambda=470 \mathrm{~nm}) / \sigma_{\mathrm{ap}}(\lambda=950 \mathrm{~nm})\right)}{\ln (470 / 950)}$. 

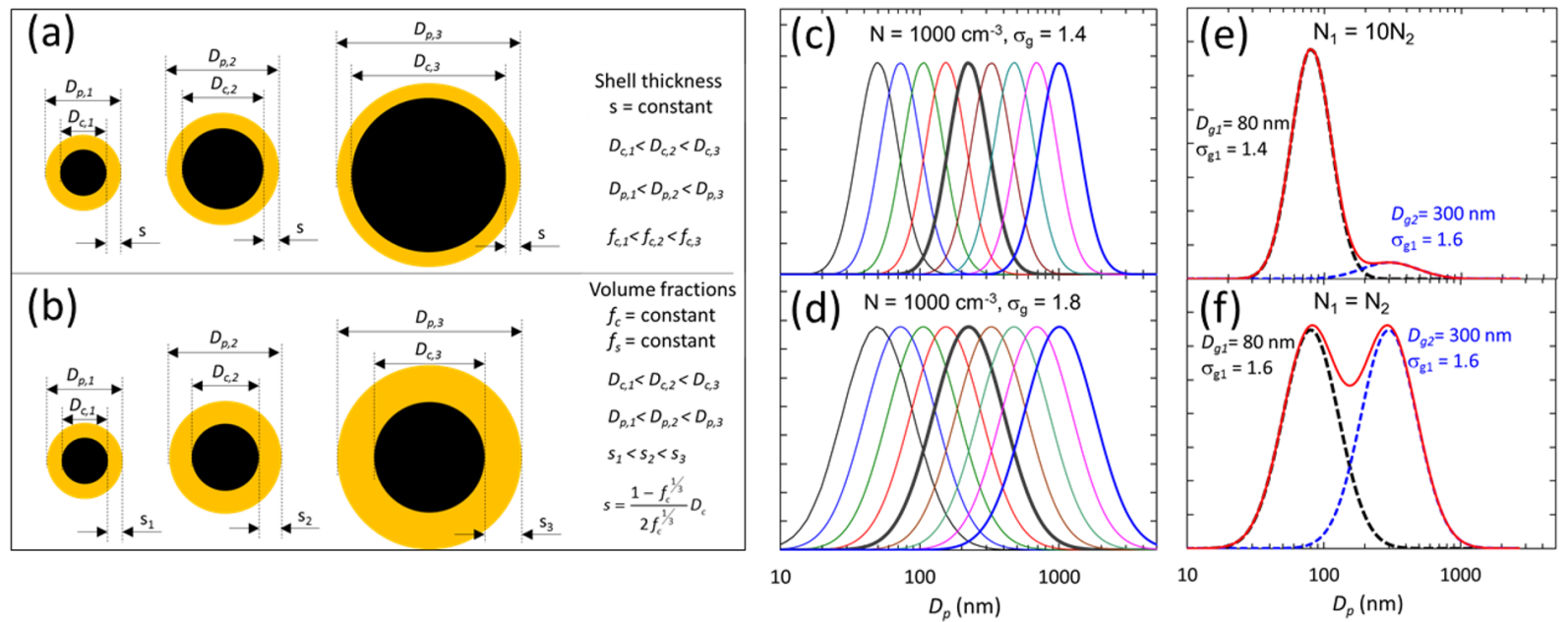

Figure 1. Examples of particles and size distributions used in the simulations: (a) particles with a BC core coated with a constant shell thickness $s$, (b) particles with constant BC core and shell volume fractions $f_{\mathrm{c}}$ and $f_{\mathrm{s}}$, (c) unimodal narrow size distributions with the geometric standard deviation of $\sigma_{\mathrm{g}}=1.4$, (d) unimodal wide size distributions with $\sigma_{\mathrm{g}}=1.8$, (e) bimodal size distributions with a dominating Aitken mode, and (f) bimodal size distributions with equal-sized Aitken and accumulation modes.

The wavelengths 470 and $950 \mathrm{~nm}$ were used as they are used also in the AE33 automatic source apportionment. In analyses of aerosol optical depth data from AERONET, $\alpha_{\mathrm{abs}}$ is often calculated for the wavelength pair 440 and $870 \mathrm{~nm}$ (Russell et al., 2010; Schuster et al., 2016). To evaluate the applicability of the simulations of the present work to AERONET data analyses, $\sigma_{\mathrm{ap}}$ was calculated also for these wavelengths, and the respective $\alpha_{\mathrm{abs}}$ was calculated from them. There are size-dependent differences between $\alpha_{\text {abs }}(470 / 950)$ and $\alpha_{\text {abs }}(440 / 870)$, but they are not big (see Figs. S1 and S2 in the Supplement), so it may safely be concluded that the results to be presented below are valid also for the AERONET data.

For the absorption due to particles from wood burning or biomass burning, Zotter et al. (2017) give the equation

$\sigma_{\mathrm{ap}, \mathrm{bb}}\left(\lambda_{2}\right)=\frac{\sigma_{\mathrm{ap}}\left(\lambda_{1}\right)-\sigma_{\mathrm{ap}}\left(\lambda_{2}\right)\left(\frac{\lambda_{1}}{\lambda_{2}}\right)^{-\alpha_{\mathrm{ff}}}}{\left(\frac{\lambda_{1}}{\lambda_{2}}\right)^{-\alpha_{\mathrm{bb}}}-\left(\frac{\lambda_{1}}{\lambda_{2}}\right)^{-\alpha_{\mathrm{ff}}}}$,

where $\alpha_{\mathrm{ff}}$ and $\alpha_{\mathrm{bb}}$ are the $\alpha_{\mathrm{abs}}$ of fossil fuel and biomassburning $\mathrm{BC}$ in the Aethalometer model. Noting that $\sigma_{\mathrm{ap}}\left(\lambda_{1}\right)=\sigma_{\mathrm{ap}}\left(\lambda_{2}\right)\left(\lambda_{1} / \lambda_{2}\right)^{-\alpha_{\mathrm{abs}}}$, the fraction of absorption due to biomass burning is

$$
\begin{aligned}
\operatorname{BB}(\%) & =100 \% \frac{\sigma_{\mathrm{ap}, \mathrm{bb}}\left(\lambda_{2}\right)}{\sigma_{\mathrm{ap}}\left(\lambda_{2}\right)} \\
& =100 \% \frac{\left(\frac{\lambda_{1}}{\lambda_{2}}\right)^{-\alpha_{\mathrm{abs}}}-\left(\frac{\lambda_{1}}{\lambda_{2}}\right)^{-\alpha_{\mathrm{ff}}}}{\left(\frac{\lambda_{1}}{\lambda_{2}}\right)^{-\alpha_{\mathrm{bb}}}-\left(\frac{\lambda_{1}}{\lambda_{2}}\right)^{-\alpha_{\mathrm{ff}}}},
\end{aligned}
$$

so that BB\% depends on the Ångström exponents $\alpha_{\mathrm{abs}}, \alpha_{\mathrm{ff}}$, and $\alpha_{\mathrm{bb}}$. Two settings for the constants were used: the one presented in the AE33 manual, $\alpha_{\mathrm{ff}}=1$ and $\alpha_{\mathrm{bb}}=2$; and the one presented by Zotter et al. (2017), $\alpha_{\mathrm{ff}}=0.9$ and $\alpha_{\mathrm{bb}}=1.68$. The symbols and their definitions are presented in Table 1 .

\section{Results and discussion}

\subsection{Single particles}

The absorption Ångström exponent $\alpha_{\mathrm{abs}}$ and the fraction of biomass-burning BC for single coated particles are shown in Fig. 2. The dashed lines in Fig. 2a, c, and e show the core diameter $D_{\text {core }}$ of particles that have the same diameter $D_{\mathrm{p}}$ at all shell thicknesses. In Fig. $2 \mathrm{~b}, \mathrm{~d}$, and $\mathrm{f}$ the dashed lines show the particle diameter $D_{\mathrm{p}}$ and $f_{\mathrm{s}}$ of particles that have the same $D_{\text {core }}$ at all shell volume fractions $f_{\mathrm{s}}$ in the range $f_{\mathrm{s}} \leq 99 \%$. The dependence of $\alpha_{\mathrm{abs}}$ on core and shell is presented twice. This is apparently superfluous, but they are visualizations that complement each other.

The first approach (Fig. 2a, c, and e) shows that when $D_{\text {core }}<\sim 150 \mathrm{~nm}$ and $s>\sim 25-50 \mathrm{~nm}$ the absorption Ångström exponent $\alpha_{\mathrm{abs}}>1.4$. The respective BB fractions are larger than about $40 \%$ or $60 \%$ for the Aethalometer model parameters of $\alpha_{\mathrm{ff}}=1, \alpha_{\mathrm{bb}}=2$ (pair 1) and $\alpha_{\mathrm{ff}}=0.9$, $\alpha_{\mathrm{bb}}=1.68$ (pair 2), respectively. Figure $2 \mathrm{a}$ also shows that for $D_{\text {core }}<\sim 100 \mathrm{~nm}$ there are two maxima of the $\alpha_{\mathrm{abs}}$ when the shell grows thicker. In the second maximum, $\alpha_{\text {abs }}>\sim 1.6$. As a result the BB fractions would be $>60 \%$ and even $>100 \%$ for the two Aethalometer model parameter pairs. When $D_{\text {core }}$ is in the range of $\sim 170-200 \mathrm{~nm}$, $\alpha_{\text {abs }} \approx 1$ and $\alpha_{\text {abs }}$ decreases with a growing $s$. For larger core diameters the absorption Ångström exponent is even 
Table 1. Nomenclature.

\begin{tabular}{|c|c|c|c|}
\hline Symbol & Definition & Unit & Equation \\
\hline$D_{\mathrm{p}}$ & Particle diameter & $\mathrm{nm}$ & $(1)$ \\
\hline$D_{\text {core }}$ & Diameter of the $\mathrm{BC}$ core particle & $\mathrm{nm}$ & (1) \\
\hline$D_{\mathrm{g}}$ & Geometric mean diameter of a size distribution & $\mathrm{nm}$ & \\
\hline$D_{\mathrm{g}, \text { core }}$ & Geometric mean diameter of the $\mathrm{BC}$ core size distribution & $\mathrm{nm}$ & \\
\hline$D_{\mathrm{g} 1}$ & $D_{\mathrm{g}}$ of the first mode of a bimodal size distribution & $\mathrm{nm}$ & \\
\hline$D_{\mathrm{g} 2}$ & $D_{\mathrm{g}}$ of the second mode of a bimodal size distribution & $\mathrm{nm}$ & \\
\hline$\sigma_{\mathrm{g}}$ & Geometric standard deviation of a size distribution & - & \\
\hline$\sigma_{\mathrm{g}, \text { core }}$ & Geometric standard deviation of the $\mathrm{BC}$ core size distribution & - & \\
\hline$\sigma_{\mathrm{g} 1}$ & $\sigma_{\mathrm{g}}$ of the first mode of a bimodal size distribution & - & \\
\hline$\sigma_{\mathrm{g} 2}$ & $\sigma_{\mathrm{g}}$ of the second mode of a bimodal size distribution & - & \\
\hline$n\left(D_{\mathrm{p}}, D_{\mathrm{g}}, \sigma_{\mathrm{g}}\right)$ & Lognormal particle number size distribution & $\mathrm{cm}^{-3}$ & \\
\hline$N_{1}$ & Number concentration of the first mode of a bimodal size distribution & $\mathrm{cm}^{-3}$ & \\
\hline$N_{2}$ & Number concentration of the second mode of a bimodal size distribution & $\mathrm{cm}^{-3}$ & \\
\hline$N_{i}$ & Number concentration of particle size $D_{\mathrm{p}, i}$ & $\mathrm{~cm}^{-3}$ & (3) \\
\hline$V_{\mathrm{p}}$ & Particle volume & $\mathrm{m}^{3}$ & (1) \\
\hline$V_{\text {core }}$ & Volume of the BC core & $\mathrm{m}^{3}$ & (1) \\
\hline$f_{\mathrm{c}}$ & Core volume fraction & - & (1) \\
\hline$f_{\mathrm{s}}$ & Shell volume fraction & - & \\
\hline$s$ & Shell thickness & $\mathrm{nm}$ & (1) \\
\hline$R$ & Ratio of the particle diameter to the $\mathrm{BC}$ core diameter $\left(D_{\mathrm{p}}\right.$-to- $D_{\text {core }}$ ratio) & - & (2) \\
\hline$R_{N\left(D_{\mathrm{p}}\right)}$ & Number-weighted $D_{\mathrm{p}}$-to- $D_{\text {core }}$ ratio & - & (3) \\
\hline$R_{i}$ & $D_{\mathrm{p}}$-to- $D_{\text {core }}$ ratio of the particle diameter $D_{\mathrm{p}, i}$ & - & (3) \\
\hline$\sigma_{\mathrm{ap}}(\lambda)$ & Absorption coefficient at the wavelength $\lambda$ & $\mathrm{Mm}^{-1}$ & (4) \\
\hline$\sigma_{\mathrm{ap}, \mathrm{bb}}(\lambda)$ & Absorption coefficient of particles from biomass burning at the wavelength $\lambda$ & $\mathrm{Mm}^{-1}$ & (6) \\
\hline$Q_{\mathrm{a}}$ & Absorption efficiency & - & (4) \\
\hline$m_{\text {core }}$ & Complex refractive index of the $\mathrm{BC}$ core & - & (4) \\
\hline$m_{\text {shell }}$ & Complex refractive index of the shell & - & (4) \\
\hline$\alpha_{\mathrm{abs}}$ & Absorption Ångström exponent & - & \\
\hline$\alpha_{\mathrm{abs}}\left(\lambda_{1} / \lambda_{2}\right)$ & Absorption Ångström exponent for the wavelength pair $\lambda_{1}, \lambda_{2}$ & - & $(5)$ \\
\hline$\alpha_{\mathrm{ff}}$ & $\alpha_{\mathrm{abs}}$ of fossil fuel $\mathrm{BC}$ in the Aethalometer model & - & (6) \\
\hline$\alpha_{\mathrm{bb}}$ & $\alpha_{\mathrm{abs}}$ of biomass-burning $\mathrm{BC}$ in the Aethalometer model & - & (6) \\
\hline
\end{tabular}

smaller. When $D_{\text {core }}>200 \mathrm{~nm}, \alpha_{\text {abs }}<1$ and even negative for $D_{\text {core }}>\sim 360 \mathrm{~nm}$. Further, when $D_{\text {core }}>200 \mathrm{~nm}, \alpha_{\text {abs }}$ does not grow essentially at all as a function of $s$.

The visualization of $\alpha_{\mathrm{abs}}$ as a function of shell volume fraction $f_{\mathrm{s}}$ and particle full diameter $D_{\mathrm{p}}$ (Fig. 2b) shows some other features. When $D_{\mathrm{p}}<50 \mathrm{~nm}, \alpha_{\text {abs }}$ varies in the range of 1.0-1.1, and it does not depend on $f_{\mathrm{s}}$, but in the $D_{\mathrm{p}}$ range of about $100-300 \mathrm{~nm} \alpha_{\mathrm{abs}}$ depends strongly on $f_{\mathrm{s}}$. When $D_{\mathrm{p}} \approx 500 \mathrm{~nm}, \alpha_{\mathrm{abs}}<1$ for almost all shell volume fractions, up to $f_{\mathrm{s}} \sim 99 \%$. For larger particles $\alpha_{\mathrm{abs}}$ is close to 0 at all shell volume fractions.

The visualization also shows that the $\alpha_{\mathrm{abs}}$ value of 1 , usually considered an indication of $\mathrm{BC}$, is not a result of an unambiguous $D_{\text {core }}-s$ (Fig. 2 a) or $D_{\mathrm{p}}-f_{\mathrm{s}}$ (Fig. 2b) combination.

\subsection{Unimodal BC core size distributions, same coating thickness for all sizes}

For single particles $\alpha_{\text {abs }}$ depends clearly on both the core size and the shell thickness. However, in real atmospheric studies the wavelength dependency of absorption by particle size distributions is measured. Here these were first modeled by assuming that pure $\mathrm{BC}$ particle size distributions get coated with ammonium sulfate layers so that the shell thickness is independent of particle size as visualized in Fig. 1a. For example, the shell thickness on a $50 \mathrm{~nm}$ BC particle would be the same as on a $200 \mathrm{~nm}$ particle, which means the shell volume fractions are not the same. The BC core geometric mean diameter $\left(D_{\mathrm{g}, \text { core }}\right)$ was varied from 50 to $200 \mathrm{~nm}$ at $10 \mathrm{~nm}$ intervals. The geometric standard deviations of the size distributions were $\sigma_{\mathrm{g}}=1.4, \sigma_{\mathrm{g}}=1.6$, and $\sigma_{\mathrm{g}}=1.8$, representing narrow, average, and wide size distributions. The shell thickness $s$ varied from 0 to $250 \mathrm{~nm}$ at $1 \mathrm{~nm}$ intervals. Absorption coefficient and subsequently $\alpha_{\text {abs }}$ was calculated for the full size distribution 3-2500 $\mathrm{nm}$. 

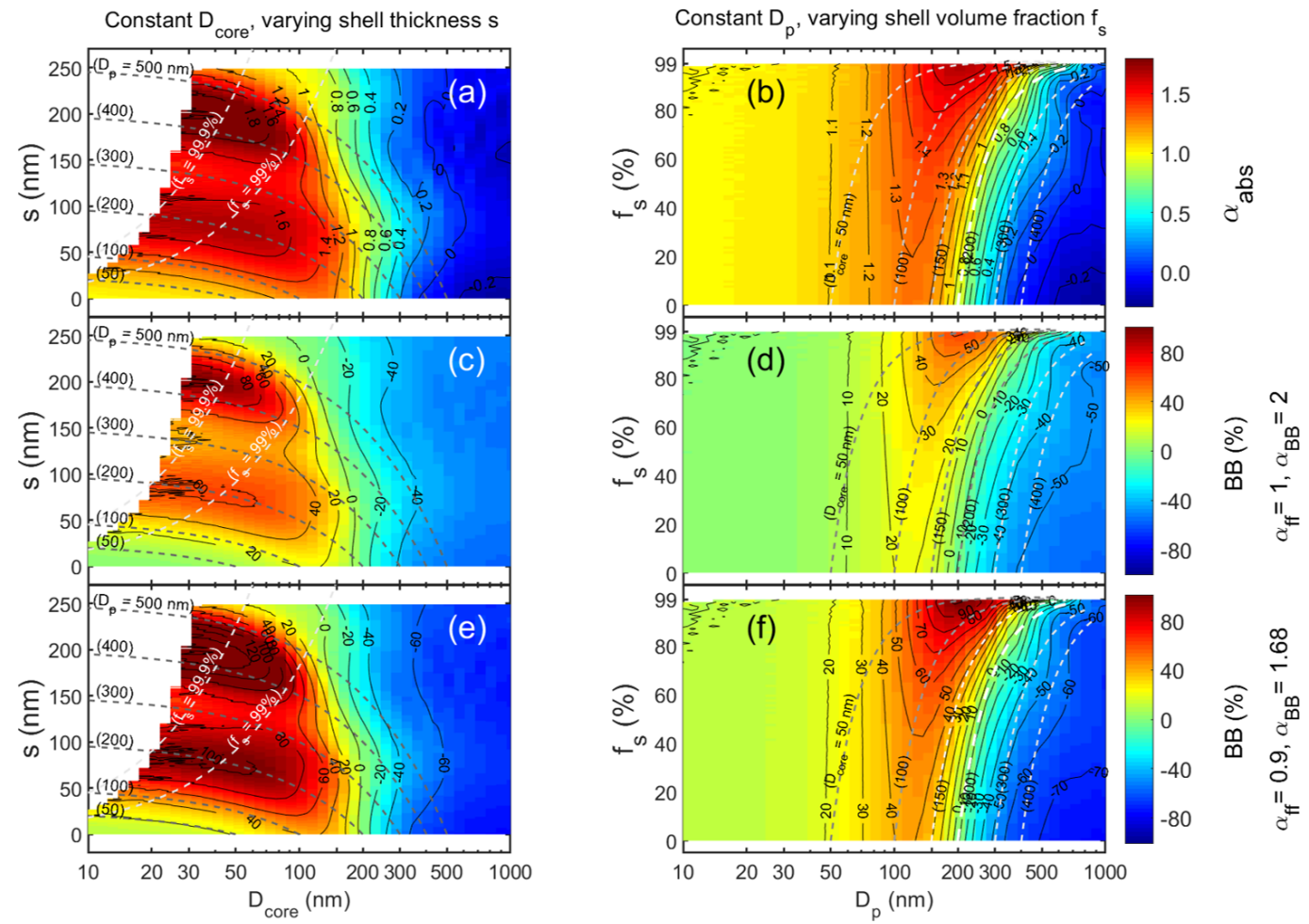

Figure 2. Absorption Ångström exponent $\left(\alpha_{\mathrm{abs}}\right)$ and the fraction of biomass-burning BC calculated from it for single coated particles $(\mathbf{a}, \mathbf{c}, \mathbf{e})$ as a function of $\mathrm{BC}$ core diameter $\left(D_{\text {core }}\right)$ and shell thickness $(s)$ and $(\mathbf{b}, \mathbf{d}, \mathbf{f})$ as a function of particle diameter $\left(D_{\mathrm{p}}=D_{\text {core }}+2 s\right)$ and shell volume fraction $f_{\mathrm{S}}$ in the range $f_{\mathrm{S}} \leq 99 \%$. In panels $(\mathbf{a}),(\mathbf{c})$, and (e), the dark dashed lines show the $D_{\text {core }}$ and $s$ of particles that have the same $D_{\mathrm{p}}$ - written in parentheses - at all shell thicknesses, and the light dashed lines show the shell thicknesses that correspond to $f_{\mathrm{s}}=99 \%$ and $99.9 \%$. In panels (b), (d), and (f), the dashed lines show the $D_{\mathrm{p}}$ and $f_{\mathrm{s}}$ of particles that have the same $D_{\text {core }}-$ written in parentheses - at all shell volume fractions. The color bars are common for panels (a) and (b), (c) and (d), and (e) and (f).

(a)

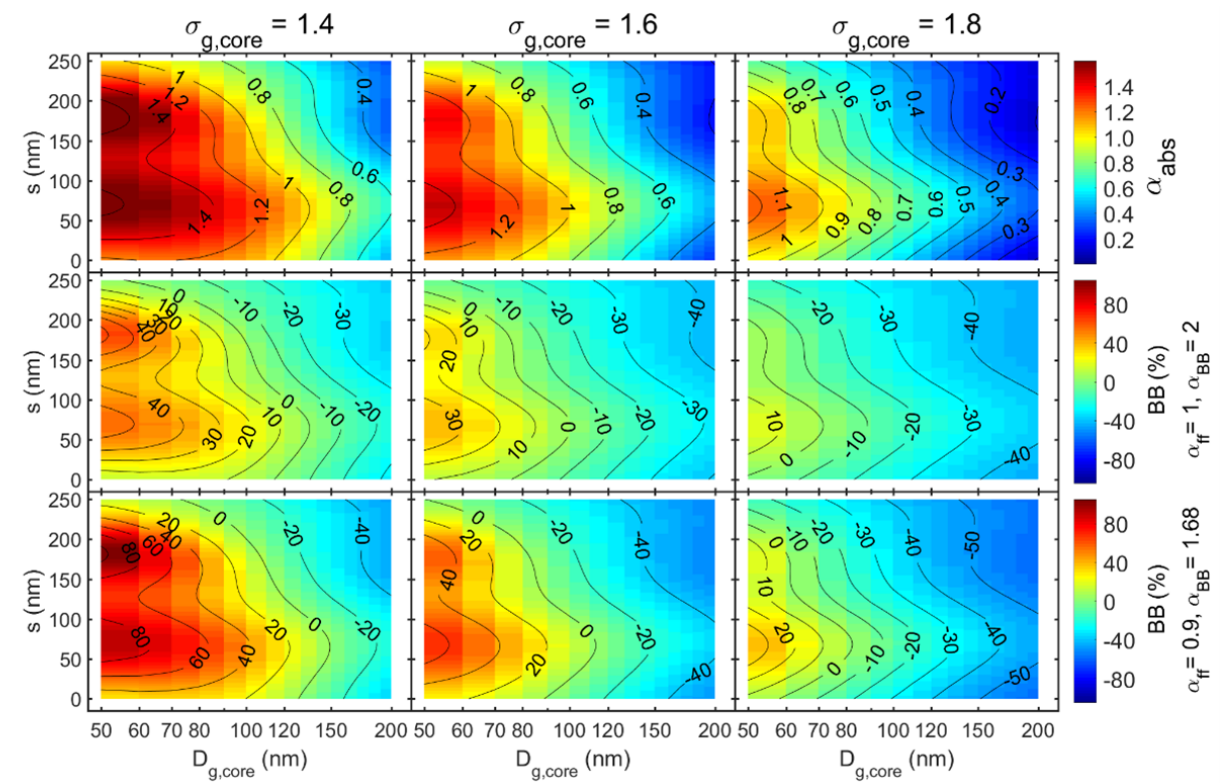

Figure 3. Unimodal particle size distributions with a size-independent shell thickness $(s)$ for three widths of the core size distributions: $\sigma_{\mathrm{g}, \text { core }}=1.4,1.6$, and 1.8. (a) Absorption Ångström exponent $\left(\alpha_{\mathrm{abs}}\right)$ and the fraction of biomass-burning $\mathrm{BC}(\mathrm{BB}(\%))$ calculated from it with the Aethalometer model constants of (b) $\alpha_{\mathrm{ff}}=1$ and $\alpha_{\mathrm{bb}}=2$ and (c) $\alpha_{\mathrm{ff}}=0.9$ and $\alpha_{\mathrm{bb}}=1.68$ vs. the geometric mean diameter of the core $\left(D_{\mathrm{g}, \text { core }}\right)$. 
The results are first shown as a function of $D_{\mathrm{g}, \text { core }}$ and shell thickness $s$ for the three size distribution widths (Fig. 3). There are both similarities and differences compared with the corresponding relationships of single particles (Fig. 2). For example, for single particles $\alpha_{\text {abs }} \approx 1$ at $D_{\text {core }} \approx 180 \mathrm{~nm}$ for shell thicknesses $s \approx 0-70 \mathrm{~nm}$ as shown by the almost vertical $\alpha_{\text {abs }}=1$ isoline in Fig. 2a, whereas for the size distributions with $\sigma_{\mathrm{g} \text {,core }}>1$ the respective isoline is a strong function of both $s$ and $\sigma_{\mathrm{g}, \text { core }}$ (Fig. 3a). At all widths of the size distribution, $\alpha_{\mathrm{abs}}$ increases with increasing shell thickness and then starts decreasing. For small core sizes $\left(D_{\mathrm{g}, \text { core }}<\sim 80 \mathrm{~nm}\right) \alpha_{\mathrm{abs}}$ also has a second maximum when the size distribution is narrow. The width of the size distribution has a clear effect on the $\alpha_{\mathrm{abs}}$ : for all core sizes and shell thicknesses $\alpha_{\mathrm{abs}}$ decreases with increasing $\sigma_{\mathrm{g}, \text { core }}$.

Both for single particles and size distributions the first maximum of $\alpha_{\mathrm{abs}}$ is the smaller the larger the $D_{\mathrm{g}, \text { core }}$ and $\sigma_{\mathrm{g}, \text { core }}$ are (Fig. 4a). The first maximum is reached at shell thickness $s \approx 70 \pm 5 \mathrm{~nm}$ for all size distribution widths although for single particles the variability of the shell thickness corresponding to the first maximum is larger (Fig. 4b). The first maximum $\alpha_{\mathrm{abs}}$ results in apparent BB fractions of up to $\sim 100 \%$ for single particles and in the range from $0 \%$ to $\sim 80 \%$ for the size distributions, and again the $\mathrm{BB}(\%)$ is smaller the larger the $D_{\mathrm{g}, \text { core }}$ and $\sigma_{\mathrm{g}}$ are (Fig. $4 \mathrm{c}$ and d).

This approach is further followed by plotting the parameters as a function of shell thickness for three different BC core diameters, 50, 70, and $90 \mathrm{~nm}$ of single particles and core size distributions with the geometric standard deviations of $\sigma_{\mathrm{g}, \text { core }}=1.4,1.6$, and 1.8 (Fig. 5). This analysis can be considered a description of what may happen to the size distribution, $\alpha_{\mathrm{abs}}$, and the apparent $\mathrm{BB}(\%)$ during condensational growth on fresh small $\mathrm{BC}$ cores if the growing shell thickness were independent of the core diameter, even if this is unrealistic. The shell volume fraction $f_{\mathrm{s}}$ increases to $>99.9 \%$ when the shell thickness grows from $s=0$ to $250 \mathrm{~nm}$ on single $50 \mathrm{~nm}$ particles but to lower fractions for the wider size distributions and larger core sizes so that for $D_{\mathrm{g}, \text { core }}=90 \mathrm{~m}$ and $\sigma_{\mathrm{g}}=1.8, f_{\mathrm{s}} \approx 98 \%$ even with $s=250 \mathrm{~nm}$ (Fig. 5a). The geometric mean diameter $D_{\mathrm{g}}$ of the whole size distribution grows to $\sim 600 \mathrm{~nm}$ when the shell thickness grows to $250 \mathrm{~nm}$, with minimal differences between the original widths (Fig. 5b). The width of the size distribution, i.e., $\sigma_{\mathrm{g}}$, decreases fast to $<1.2$ (Fig. 4c). Such values correspond to very narrow size distributions, which are not really observed in the real atmosphere.

The number-weighted $D_{\mathrm{p}}$-to- $D_{\text {core }}$ ratio $R_{N\left(D_{\mathrm{p}}\right)}$, Eq. (3), was calculated for the size range $90-600 \mathrm{~nm}$ to present the numbers comparable with papers that present shell-to-core ratios of refractory BC (rBC) obtained from SP2 measurements. For instance, Kondo et al. (2011) measured urban air of Tokyo and obtained the median $R=1.1$ with a range up to about 1.3 , the mean $D_{\mathrm{g}}=64 \pm 6 \mathrm{~nm}$, and $\sigma_{\mathrm{g}}=1.66 \pm 0.12$. Moteki et al. (2007) conducted SP2 measurements in an aircraft in urban plumes on the Japanese coast. They fitted the

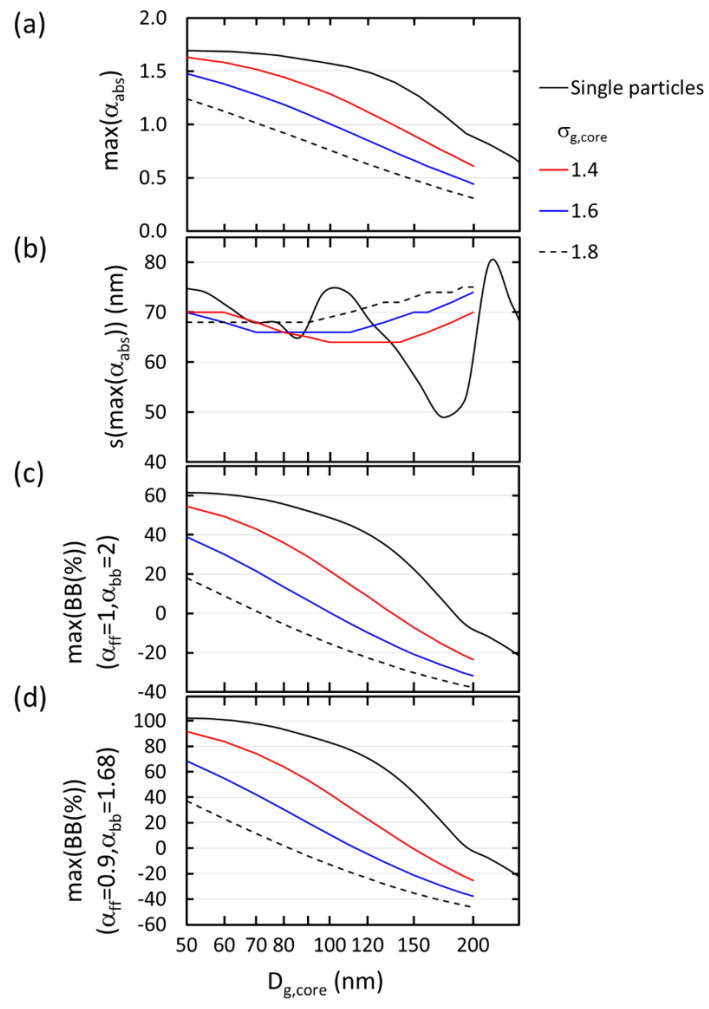

Figure 4. Size distribution dependence of the first maximum of $\alpha_{\mathrm{abs}}$ when a size-independent shell grows on a BC core: (a) the first maximum value of $\alpha_{\mathrm{abs}}$, (b) the shell thickness at the maximum $\alpha_{\mathrm{abs}}$, (c) maximum biomass-burning fraction with the Aethalometer model constants $\alpha_{\mathrm{ff}}=1$ and $\alpha_{\mathrm{bb}}=2$, and (d) maximum biomassburning fraction with the Aethalometer model constants $\alpha_{\mathrm{ff}}=0.9$ and $\alpha_{\mathrm{bb}}=1.68$ as a function of the BC core geometric mean diameter $\left(D_{\mathrm{g}, \text { core }}\right)$ and geometric standard deviation $\left(\sigma_{\mathrm{g}, \text { core }}\right)$.

data with lognormal size distributions with mass median diameters (MMDs) of 190 and $210 \mathrm{~nm}$ and $\sigma_{\mathrm{g}}$ of 1.55 and 1.45 for fresh and aged $\mathrm{rBC}$, respectively. The fresh $\mathrm{rBC}$ was thinly coated with $R<2$ and the aged $\mathrm{rBC}$ thickly coated with $R \sim 2$. The MMD and $\sigma_{\mathrm{g}}$ values yield $D_{\mathrm{g}}=107$ and $139 \mathrm{~nm}$. Shiraiwa et al. (2008) measured the mixing state and size distribution of BC aerosol with an SP2 at a remote island (Fukue) in Japan. They observed that the BC number median diameters were in the range of $120-140 \mathrm{~nm}$ in every air mass type, and the median shell / core diameter ratio $(R)$ in different air masses varied in the range of 1.21.6. However, they also observed that the fraction of $R$ values in the range 2-3.5 was not negligible either (Fig. 9 of Shiraiwa et al., 2008). Such values correspond to the range where $\alpha_{\mathrm{abs}}$ first grows to $>1.6$ for the narrow $\left(\sigma_{\mathrm{g} \text {,core }}=1.4\right)$ $\mathrm{BC}$ core size distribution that has the smallest geometric mean size $\left(D_{\mathrm{g} \text {,core }}=50 \mathrm{~nm}\right)$ but to lower values for the wider size distributions that have larger $D_{\mathrm{g}, \text { core }}$ (Fig. $5 \mathrm{c}$ and d). The first maximum is reached at shell thicknesses of $s \approx 70 \mathrm{~nm}$ that correspond to $R \approx 2$ and shell volume frac- 
(a)

(b)
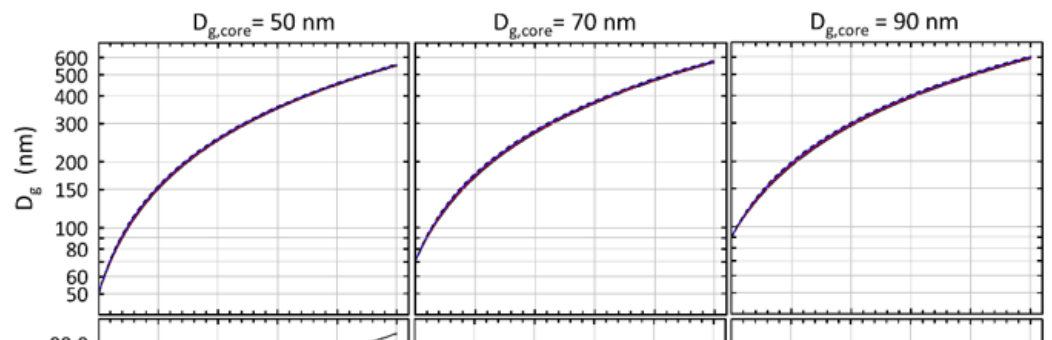
- Single
particles

$\sigma_{\mathrm{g}, \mathrm{core}}$

$$
\frac{\widehat{9}}{4}
$$

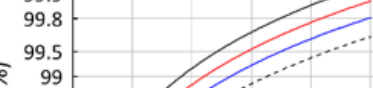

(c)

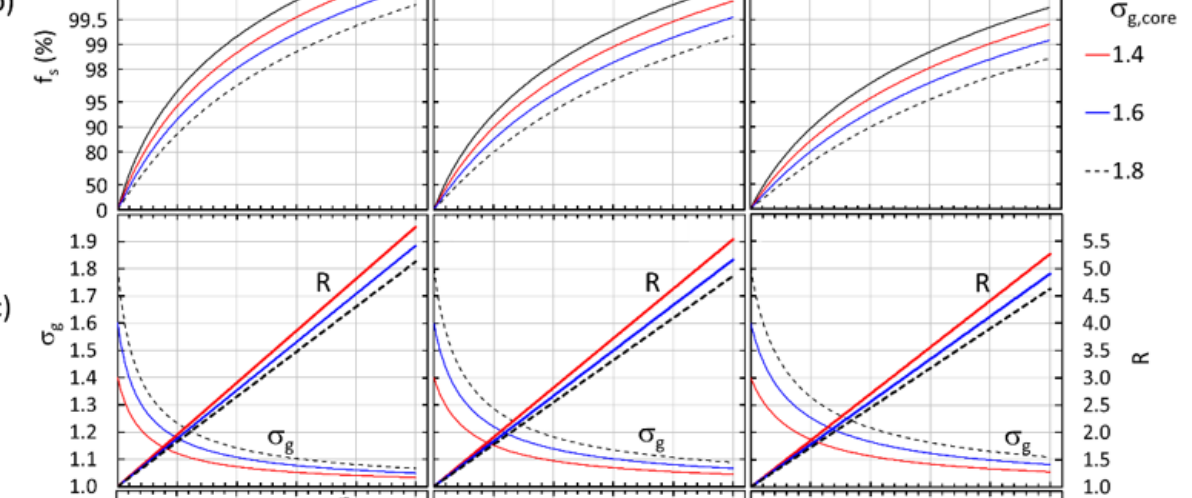

(d)

(e)
1.6
1.4
ชี 1.2
0.6
0.4
0.2

1.8

1.8
1.6
1.4

ชో 1.0

140
" 120
ชึ 100

ii 80

of 60

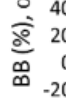

${ }^{-40}$

i- 120

8 80

(f)

के

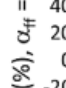

$\left(\begin{array}{ccc}\infty \\ \infty\end{array}-20\right.$

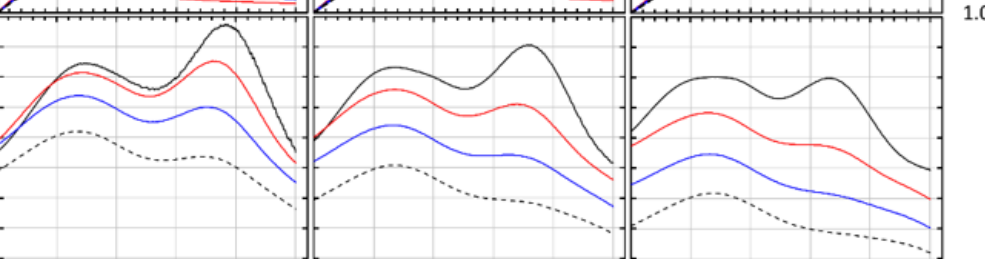

$-40$

$\begin{array}{lll}0 & 50 & 100 \quad 150 \\ s(n m) & 200\end{array}$

Figure 5. Examples of the growth of a non-size-dependent scattering shell on $\mathrm{BC}$ core size distributions with $D_{\mathrm{g}, \text { core }}=50,70$, and $90 \mathrm{~nm}$ and on single BC particles. (a) Geometric mean diameter, (b) shell volume fraction, (c) geometric standard deviation and $D_{\mathrm{p}}$-to- $D_{\mathrm{core}}$ ratio $(R),(\mathbf{d})$ absorption Ångström exponent, (e) $\mathrm{BB}(\%)$ with the Aethalometer model constants $\alpha_{\mathrm{ff}}=1$ and $\alpha_{\mathrm{bb}}=2$, and (d) biomass-burning fraction with the Aethalometer model constants $\alpha_{\mathrm{ff}}=0.9$ and $\alpha_{\mathrm{bb}}=1.68$ as a function shell thickness $s$.

tions of $f_{\mathrm{s}} \approx 90 \pm 8 \%$ (Fig. 5b). Schwarz et al. (2008) reported statistics of $\mathrm{rBC}$ mass size distributions in urban aerosol: $f_{\mathrm{s}}=9 \pm 6 \%, s=20 \pm 10 \mathrm{~nm}, \mathrm{MMD}=170 \mathrm{~nm}$, and $\sigma_{\mathrm{g}}$ of 1.71 , which yields $D_{\mathrm{g}}=72 \mathrm{~nm}$; in biomass-burning emissions: $f_{\mathrm{s}}=70 \pm 9 \%, s=65 \pm 12 \mathrm{~nm}, \mathrm{MMD}=210 \mathrm{~nm}$, and $\sigma_{\mathrm{g}}=1.43$, which yields $D_{\mathrm{g}}=143 \mathrm{~nm}$; and in back- ground continental aerosol: $f_{\mathrm{s}}=46 \pm 3 \%, s=48 \pm 14 \mathrm{~nm}$, $\mathrm{MMD}=210 \mathrm{~nm}$, and $\sigma_{\mathrm{g}}=1.55$, which yields $D_{\mathrm{g}}=118 \mathrm{~nm}$.

The referenced studies show that the $s, R$, and $f_{\mathrm{s}}$ values are in the range observed in ambient measurements studies. What is not realistic in atmospheric aerosol is the width of the size distribution, which soon decreases to $\sigma_{\mathrm{g}}<1.2$ (Fig. 5c). 
After reaching the first maximum, $\alpha_{\mathrm{abs}}$ decreases, and for single particles and the narrowest core size distributions it starts growing again and reaches a second maximum at shell thicknesses of $s \approx 170 \mathrm{~nm}$, which corresponds to $R>4$ and $f_{\mathrm{S}}>98 \%$. Such $s$ and $R$ values are not in the range observed in the abovementioned studies, nor are the low geometric standard deviations of $\sigma_{\mathrm{g}}<1.1$ realistic, so the second maximum can be considered as a theoretical value only. For size distributions with $D_{\mathrm{g} \text {,core }}>70 \mathrm{~nm}$ there is no second maximum of $\alpha_{\text {abs. }}$.

As $\alpha_{\text {abs }}$ increases and decreases, it is clear that this applies to $\mathrm{BB}(\%)$ as well (Fig. $5 \mathrm{~d}-\mathrm{e})$. For the smallest core sizes $\left(D_{\mathrm{g}, \text { core }}=50 \mathrm{~nm}\right)$ and the narrowest size distributions $\left(\sigma_{\mathrm{g}, \text { core }}=1.4\right)$, the first maximum $\mathrm{BB}(\%)$ may be as high as $\sim 90 \%$ when the values of $\alpha_{\mathrm{ff}}=0.9$ and $\alpha_{\mathrm{bb}}=1.68$ are used in Eq. (7) but lower, $\sim 50 \%$, when the values of $\alpha_{\mathrm{ff}}=1$ and $\alpha_{\mathrm{bb}}=2$ are used. For the wider core size distributions the $\mathrm{BB}(\%)$ fractions are lower. For the widest core size distributions $\left(\sigma_{\mathrm{g}, \text { core }}=1.8\right)$ clearly positive $\mathrm{BB}(\%)$ values are reached only for the smallest core sizes.

Figure 5 can also be considered a proxy for a time series of the development of $\alpha_{\mathrm{abs}}$ and derived BB(\%) after emission of $\mathrm{BC}$ particles and their growth by condensation of nonabsorbing compounds. A similar development $-\alpha_{\text {abs }}$ values increase to $>1.3$ and decrease to $<0.9$ during a several-daylong pollution episode during which the $D_{\mathrm{g}}$ of the whole size distribution grew possibly by condensation - was observed at the Station for Observing Regional Processes of the Earth System (SORPES) in Nanjing, China (Fig. 9 of Shen et al., 2018). There was no SP2 available for the core-shell structure measurements in that study, so it cannot really be proven that the observed $\alpha_{\text {abs }}$ development was due to condensational growth even though it seems a good explanation and is qualitatively in line with Fig. 5.

\subsection{Unimodal size distributions with the same $\mathrm{BC}$ core fraction for all sizes}

The second approach is to assume that the BC core fraction - or equivalently the shell volume fraction - is the same for all sizes, which means that the shell thickness increases with size as was visualized in Fig. 1b. This can be considered to be a result of aging of BC by not only condensational growth but also by cloud processing. The latter would lead to thick shells on particles activated into cloud droplets that would absorb for instance $\mathrm{SO}_{2}$ and $\mathrm{NH}_{3}$ and that would not rain but later get back into the aerosol phase by evaporation of cloud water. The constant volume fraction is not realistic but neither is the constant shell thickness. Both can be considered to be approximations.

In this approach the geometric standard deviations of the whole size distributions were set to $\sigma_{\mathrm{g}}=1.4,1.6$, and 1.8, and the shell volume fractions $f_{\mathrm{s}}$ were set to vary from $0 \%$ to $99 \%$. The resulting $\alpha_{\mathrm{abs}}$ and $\mathrm{BB}(\%)$ are presented as a function of $D_{\mathrm{g}}, f_{\mathrm{s}}$, and $\sigma_{\mathrm{g}}$ (Fig. 6). They are comparable with the analogous plots for single particles, i.e., $\sigma_{\mathrm{g}}=1.0$ (Fig. $2 \mathrm{~b}$, $\mathrm{d}$, and f). Note that from Eq. (2) it follows that the assumption of a constant $f_{\mathrm{s}}$ means that also the $D_{\mathrm{p}}$-to- $D_{\text {core }}$ ratio $R$ is constant and that the $f_{\mathrm{s}}$ range of $0 \%$ to $99 \%$ corresponds to the $R$ range of 1 to 4.6. Figure 6 therefore has two $y$ axes: one showing the $f_{\mathrm{s}}$ and the other the corresponding $R$ values.

Several observations can be made from Fig. 6. One of them is that the isoline of $\alpha_{\mathrm{abs}}=1$ grows with growing $D_{\mathrm{g}}$ for each of the size distribution widths $\left(\sigma_{\mathrm{g}}\right)$ but decreases with growing $\sigma_{\mathrm{g}}$. Another is that the wider the size distribution is, the lower the $\alpha_{\mathrm{abs}}$ and $\mathrm{BB}(\%)$ are at any given shell volume fraction. The third one is that for all three widths $\alpha_{\text {abs }}$ and $\mathrm{BB}(\%)$ grows when $f_{\mathrm{s}}$ grows but that the growth is not uniformly distributed over the $f_{\mathrm{s}}$ vs. $D_{\mathrm{g}}$ space.

The last observation leads to calculations of sizedependent sensitivities of $\alpha_{\mathrm{abs}}$ to variations in $f_{\mathrm{s}}$. The sensitivity was calculated as $\mathrm{d} \alpha_{\mathrm{abs}} / \mathrm{d} f_{\mathrm{s}}$, and its unit is $\%^{-1}$. Figure $7 \mathrm{a}$ shows the sensitivities in the whole $f_{\mathrm{s}}$ range of $1 \%-99 \%$ as a function of $D_{\mathrm{g}}$ for the three size distribution widths. The sensitivity depends clearly on both $D_{\mathrm{g}}$ and $\sigma_{\mathrm{g}}$ of the size distribution, and it also varies with $f_{\mathrm{s}}$. It is very clear that $\alpha_{\mathrm{abs}}$ is most sensitive to $f_{\mathrm{s}}$ variations when $D_{\mathrm{g}}$ of the size distribution is in the accumulation-mode sizes of 100$200 \mathrm{~nm}$. The sensitivity grows fairly steadily with growing $f_{\mathrm{s}}$ until it increases very strongly for $f_{\mathrm{s}}>90 \%$ - which equals $R>2$.

Another step for visualizing the sensitivities was taken by calculating size-dependent average sensitivities of $\alpha_{\mathrm{abs}}$ and $\mathrm{BB}(\%)$ in three $f_{\mathrm{s}}$ ranges: $f_{\mathrm{s}}=0 \%-50 \%, 50 \%-90 \%$, and 90\%-99\% (Fig. 7b and c).

According to Eq. (2) the $f_{\mathrm{s}}$ ranges correspond to the $R$ ranges of 1-1.3, 1.3-2.2, and 2.2-4.6. The lines in Fig. 7b and c can be used for a rough estimate on a possible effect on $\alpha_{\mathrm{abs}}$ and $\mathrm{BB}(\%)$. For instance, if $D_{\mathrm{g}} \approx 140 \mathrm{~nm}, \sigma_{\mathrm{g}}=1.4$, and $f_{\mathrm{s}} \approx 50 \%-90 \%$, an increase in $f_{\mathrm{s}}$ from $50 \%$ to $51 \%$ leads to an $\alpha_{\text {abs }}$ increase of $\sim 0.01$ and consequently to a $\mathrm{BB}(\%)$ increase of $\sim 1 \%$ when Aethalometer model constants of $\alpha_{\mathrm{ff}}=0.9$ and $\alpha_{\mathrm{bb}}=1.68$ are used.

\subsection{Bimodal size distributions with the same BC core fraction for all sizes in the mode}

Finally, bimodal size distributions are examined briefly. The size distributions consist of two externally mixed modes that have different shell volume fractions. In both modes the shell volume fractions are size-independent as in Fig. 1b. Mode 1 is an Aitken mode with the geometric mean diameter $D_{\mathrm{g} 1}$ in the range $50-100 \mathrm{~nm}$. There are two different settings for the Aitken mode: in the first case its number concentration is 10 times larger than that of the accumulation mode, i.e., $N_{1}=10 N_{2}$; it consists of almost pure fresh BC particles with $f_{\mathrm{s} 1}=5 \%(R \approx 1.02)$; and it is narrow, $\sigma_{\mathrm{g} 1}=1.4$. In the second setting the number concentrations of the Aitken and accumulation mode are equal $\left(N_{1}=N_{2}\right)$; the Aitken mode is aged so that $f_{\mathrm{s} 1}=50 \%(R \approx 1.3)$; and it is wider, $\sigma_{\mathrm{g} 1}=1.6$. 


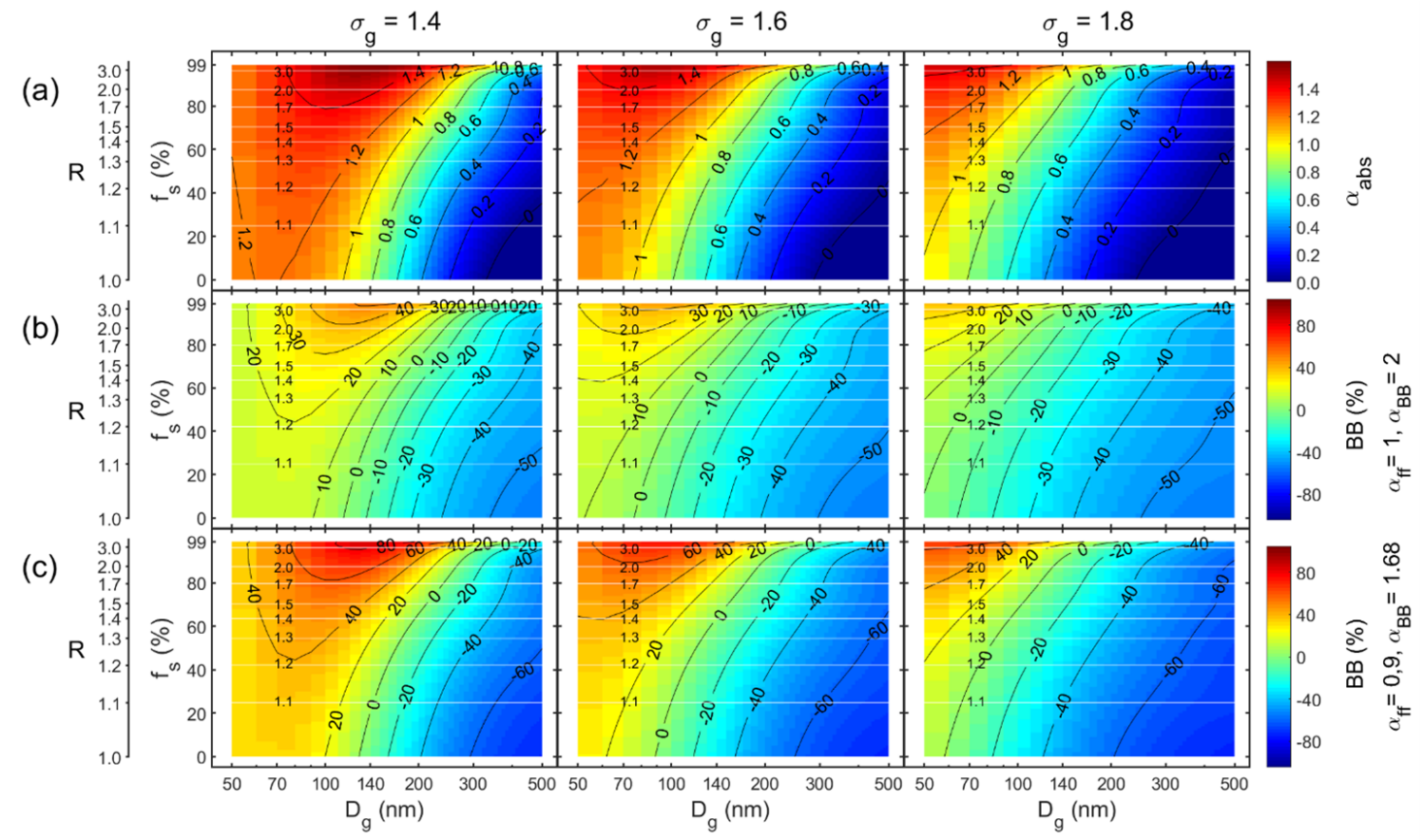

Figure 6. Unimodal particle size distributions with size-independent shell volume fractions $f_{\mathrm{S}}$ and three widths of the size distributions: $\sigma_{\mathrm{g}}=1.4,1.6$, and 1.8. (a) Absorption Ångström exponent $\left(\alpha_{\mathrm{abs}}\right)$ and the fraction of biomass-burning BC $(\mathrm{BB}(\%))$ calculated from it with the Aethalometer model constants of (b) $\alpha_{\mathrm{ff}}=1$ and $\alpha_{\mathrm{bb}}=2$ and (c) $\alpha_{\mathrm{ff}}=0.9$ and $\alpha_{\mathrm{bb}}=1.68$ vs. the geometric mean diameter of the whole size distribution $\left(D_{\mathrm{g}}\right)$. The white horizontal grid lines show constant $D_{\mathrm{p}}$-to- $D_{\text {core }}$ ratios $(=R)$.

(a)

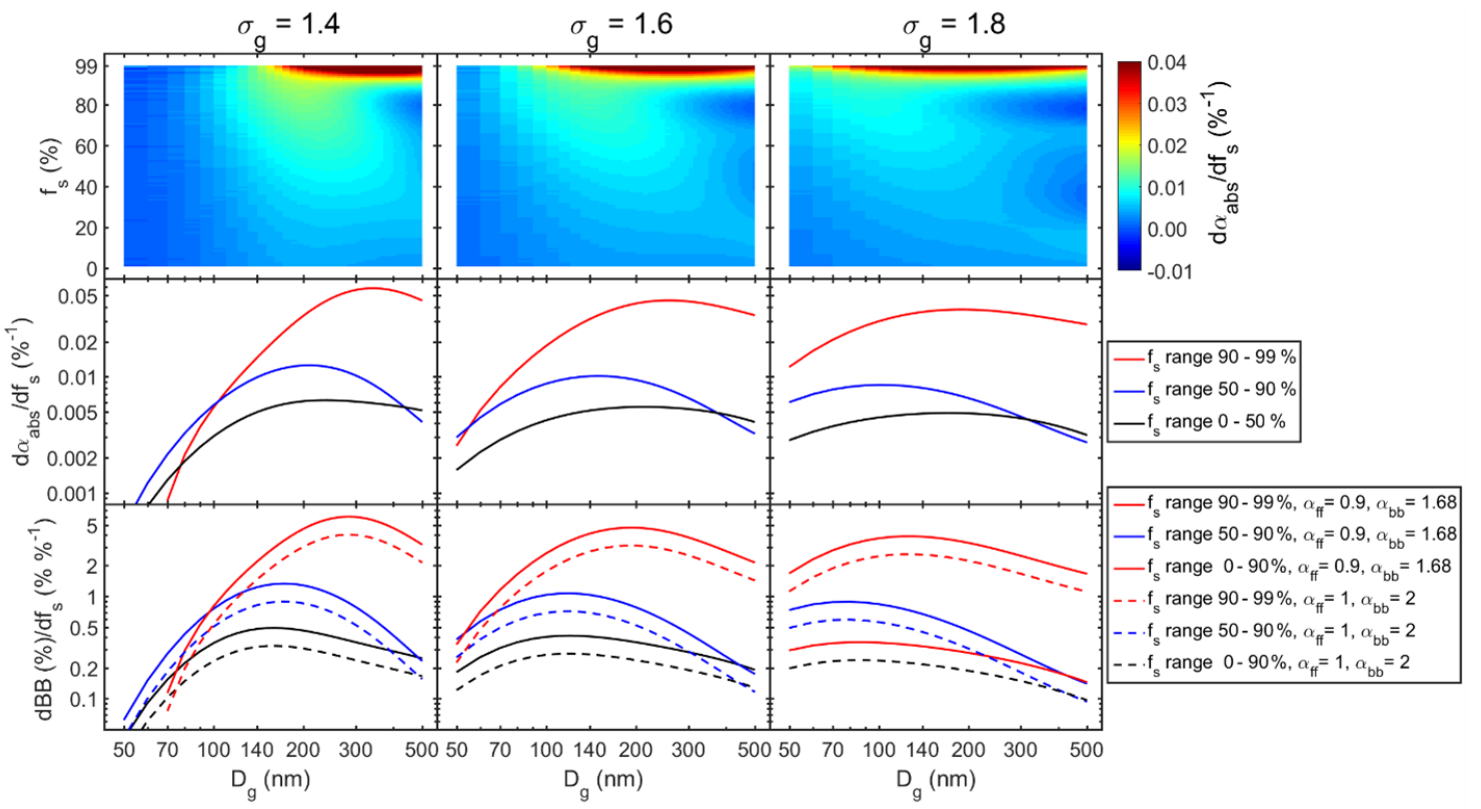

Figure 7. Size-dependent sensitivity of $\alpha_{\mathrm{abs}}$ and $\mathrm{BB}(\%)$ to variations of the shell volume fraction $f_{\mathrm{s}}$. (a) $\alpha_{\mathrm{abs}}$ sensitivity in the whole $f_{\mathrm{s}}$ range of $1 \%-99 \%$, (b) average $\alpha_{\text {abs }}$ sensitivity in three $f_{\mathrm{s}}$ ranges, and (c) average $\mathrm{BB}(\%)$ sensitivities in three $f_{\mathrm{s}}$ ranges. 
(a)

(b)

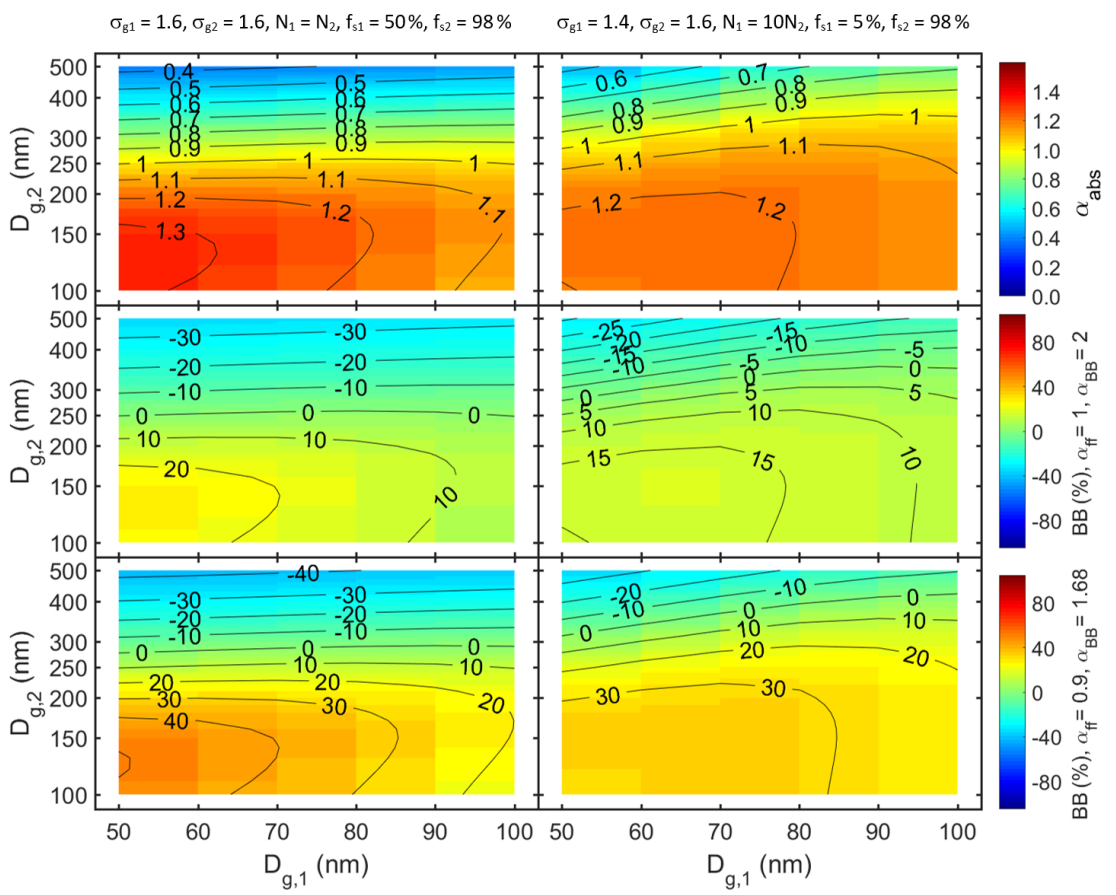

Figure 8. Bimodal particle size distributions with size-independent shell volume fractions $f_{\mathrm{s}}$ in two modes as a function of geometric mean diameters of mode $1\left(D_{\mathrm{g} 1}\right)$ and mode $2\left(D_{\mathrm{g} 2}\right)$. (a) Absorption Ångström exponent $\left(\alpha_{\mathrm{abs}}\right)$ and the fraction of biomass-burning BC (BB $\left.(\%)\right)$ calculated from it with the Aethalometer model constants of (b) $\alpha_{\mathrm{ff}}=1$ and $\alpha_{\mathrm{bb}}=2$ and (c) $\alpha_{\mathrm{ff}}=0.9$ and $\alpha_{\mathrm{bb}}=1.68$. The widths, the relative number of particles in the two modes, and the shell volume fractions of the two modes: $\sigma_{\mathrm{g} 1}=1.6, \sigma_{\mathrm{g} 2}=1.6, N_{1}=N_{2}, f_{\mathrm{s} 1}=50 \%$, and $f_{\mathrm{s} 2}=98 \%$ on the left column and $\sigma_{\mathrm{g} 1}=1.4, \sigma_{\mathrm{g} 2}=1.6, N_{1}=10 N_{2}, f_{\mathrm{s} 1}=5 \%$, and $f_{\mathrm{s} 2}=98 \%$ on the right column.

Mode 2 is an accumulation mode with the geometric mean diameter $D_{\mathrm{g} 2}$ in the range $100-500 \mathrm{~nm}, \sigma_{\mathrm{g} 2}=1.6$, and it is very aged, with $f_{\mathrm{s} 2}=98 \%(R \approx 3.7)$. The accumulation mode could be the result of cloud processing as explained above.

The results show that $\alpha_{\mathrm{abs}}$ is more sensitive to variations of the accumulation mode than of the Aitken mode (Fig. 8a). For instance, if $D_{\mathrm{g} 2}<250 \mathrm{~nm}, \alpha_{\mathrm{abs}}>1$ at all $D_{\mathrm{g}, 1}$ values. Also, if $D_{\mathrm{g}, 1}=60 \mathrm{~nm}$ and $D_{\mathrm{g} 2}$ varies in the whole range of $100-500 \mathrm{~nm}, \alpha_{\mathrm{abs}}$ varies in the range of $\sim 0.4-1.3$. When the Aitken mode dominates the number concentration $\left(N_{1}=10 N_{2}\right)$ with the fresh BC particles, the maximum $\alpha_{\mathrm{abs}} \approx 1.2$ at $D_{\mathrm{g} 1} \approx 60 \mathrm{~nm}$ and $D_{\mathrm{g} 2} \approx 140 \mathrm{~nm}$ is smaller than when the two modes have an equal amount of particles. In the latter case the maximum $\alpha_{\text {abs }}>1.3$. When the Aitken mode with $f_{\mathrm{s}}=5 \%$ dominates the number concentration, the whole size distribution moves to the region that is less sensitive to $f_{\mathrm{s}}$ variations as discussed above in Sect. 3.3. It is worth noting also that the maximum $\alpha_{\mathrm{abs}}$ and $\mathrm{BB}(\%)$ values (Fig. $8 \mathrm{~b}$ and c) are smaller than derived from the unimodal size distributions (Sect. 3.3).

\section{Summary and conclusions}

The purpose of this study is not to claim that all Aethalometer model results are wrong but that they have higher uncertainties than have been discussed in the literature. It is clear that there are $\mathrm{BrC}$ particles that have absorption Ångström exponents clearly larger than 1 , as shown in a very large number of publications. However, the size of light-absorbing particles and their coating even by purely scattering material clearly affect the wavelength dependence of absorption and thus have the potential to affect the Aethalometer model results. Since the wavelength dependency is used for source apportionment, these effects have the potential to result in contributions of wood-burning or fossil fuel emissions that are tens of percent too high or low.

There are some important results. In the modeling, $\alpha_{\mathrm{abs}}$ equals 1 or 0.9 in very rare cases, and thus $\mathrm{BB}(\%)$ was very seldom $0 \%$ even though one type of $\mathrm{BC}$ was the only absorbing material in the simulations. The shape of size distribution plays an important role. Narrow size distributions result in higher $\alpha_{\mathrm{abs}}$ and $\mathrm{BB}(\%)$ values than wide size distributions. The sensitivity of $\alpha_{\mathrm{abs}}$ and $\mathrm{BB}(\%)$ to variations in shell volume fractions is the highest for accumulation-mode particles. This is important because that is where the largest aerosol mass is. 
The goal of the paper was not to find out whether some pair of $\alpha_{\mathrm{ff}}$ and $\alpha_{\mathrm{bb}}$ is better than the other. Two well-known $\alpha_{\mathrm{ff}}$ and $\alpha_{\mathrm{bb}}$ pairs were used and shown how large the uncertainties may become just for these two pairs even if BC particles were coated by purely scattering material. The goal was not at all to find a good pair. On the contrary, the study shows that no constant values are good since in the real atmosphere BC particle size distributions are not constant, neither their mean diameter nor the coating of the particles. They all vary dynamically in the atmosphere. The study shows that any constant values will undoubtedly lead to large uncertainties of both the BB and FF fractions if no information on the size of the core or the thickness of the shell is available, even if purely scattering material is coating BC cores. As a conclusion, for the interpretation of absorption Ångström exponents it would be very important to measure BC size distributions and shell thicknesses together with the wavelength dependency of absorption.

There are obvious limitations in this study. A core-shell Mie model was used only so the work is limited to spherical particles. Fresh BC particles are usually agglomerates. There are studies that show that during aging processes these agglomerate may collapse and become closer to spherical particles, so Mie modeling probably agrees better for aged than fresh BC particles. Further, even if particles were spherical, how well can they be modeled with a Mie code when they are collected on filters? Or does light absorption then follow the spectral absorbance of the bulk materials?

This question could in principle be answered by generating spherical BC particles, coating them in an aging chamber with some non-absorbing material - for instance ammonium sulfate, and measuring both light absorption at multiple wavelengths with an Aethalometer and BC core size distributions and shell thicknesses with an SP2. If $\alpha_{\text {abs }}$ increases up to some maximum value as a function of shell thickness and then starts decreasing like in the simulations above, then the process agrees with the growth of a size-independent coating. Or if $\alpha_{\text {abs }}$ increases steadily then it suggests that the growth is size-dependent and possibly with a size-independent shell volume fraction growth rate. If these effects are observed then the uncertainties discussed in this work should be taken seriously.

On the other hand, if none of these effects were observed and the absorption Ångström exponents of the collected particles were $\approx 1$ regardless of core size and shell thickness, it would be safe to say that the Aethalometer measures the absorption spectra of the bulk materials and that the Aethalometer model yields correct results. The truth is probably somewhere between these extremes: when the filter tape is still relatively clean the particles can be modeled even with a Mie code, and for heavily loaded filters $\alpha_{\text {abs }}$ is that of bulk material. This could and should also be tested experimentally.
Code availability. The code is described in Voshchinnikov and Mathis (1999) and it is available in http://www.astro.spbu.ru/staff/ ilin2/SOFTWARE/nmie0.html.

Data availability. The data can be generated as described in Sect. 2 . No real data were used in this paper.

Supplement. The supplement related to this article is available online at: https://doi.org/10.5194/amt-14-3707-2021-supplement.

Competing interests. The author declares that there is no conflict of interest.

Special issue statement. This article is part of the special issue "Satellite and ground-based remote sensing of aerosol optical, physical, and chemical properties over China". It is not associated with a conference.

Financial support. This research has been supported by the Academy of Finland via the projects NABCEA (grant no. 296302) and ACFA (grant no. 335845) and by Business Finland via project BC Footprint (grant no. 528/31/2019).

Review statement. This paper was edited by Linlu Mei and reviewed by two anonymous referees.

\section{References}

Andreae, M. O. and Gelencsér, A.: Black carbon or brown carbon? The nature of light-absorbing carbonaceous aerosols, Atmos. Chem. Phys., 6, 3131-3148, https://doi.org/10.5194/acp-63131-2006, 2006.

Arola, A., Schuster, G., Myhre, G., Kazadzis, S., Dey, S., and Tripathi, S. N.: Inferring absorbing organic carbon content from AERONET data, Atmos. Chem. Phys., 11, 215-225, https://doi.org/10.5194/acp-11-215-2011, 2011.

Bergstrom, R. W., Pilewskie, P., Russell, P. B., Redemann, J., Bond, T. C., Quinn, P. K., and Sierau, B.: Spectral absorption properties of atmospheric aerosols, Atmos. Chem. Phys., 7, 5937-5943, https://doi.org/10.5194/acp-7-5937-2007, 2007.

Bond, T. C. and Bergstrom, R. W.: Light Absorption by Carbonaceous Particles: An Investigative Review, Aerosol Sci. Technol., 40, 27-67, 2006.

Bond, T. C., Doherty, S. J., Fahey, D. W., Forster, P. M., Berntsen, T., DeAngelo, B. J., Flanner, M. G., Ghan, S., Kärcher, B., Koch, D., Kinne, S., Kondo, Y., Quinn, P. K., Sarofim, M. C., Schultz, M. G., Schulz, M., Venkataraman, C., Zhang, H., Zhang, S., Bellouin, N., Guttikunda, S. K., Hopke, P. K., Jacobson, M. Z., Kaiser, J. W., Klimont, Z., Lohmann, U., Schwarz, J. P., Shindell, D., Storelvmo, T., Warren, S. G., and Zender, C.S.: Bounding the role of black carbon in the climate system: A sci- 
entific assessment, J. Geophys. Res.-Atmos., 118, 5380-5552, https://doi.org/10.1002/jgrd.50171, 2013.

Cazorla, A., Bahadur, R., Suski, K. J., Cahill, J. F., Chand, D., Schmid, B., Ramanathan, V., and Prather, K. A.: Relating aerosol absorption due to soot, organic carbon, and dust to emission sources determined from in-situ chemical measurements, Atmos. Chem. Phys., 13, 9337-9350, https://doi.org/10.5194/acp13-9337-2013, 2013.

Chung, C., Ramanathan, V., and Decremer, D.: Observationally constrained estimates of carbonaceous aerosol radiative forcing, P. Natl. Acad. Sci. USA, 109, 11624-11629, 2012.

Chylek, P., Lee, J. E., Romonosky, D. E., Gallo, F., Lou, S., Shrivastava, M., Carrico, C. M., Aiken, A. C., and Dubey, M. K.: Mie scattering captures observed optical properties of ambient biomass burning plumes assuming uniform black, brown, and organic carbon mixtures, J. Geophys. Res.-Atmos., 124, 1140611427, https://doi.org/10.1029/2019JD031224, 2019.

Devi, J. J., Bergin, M., McKenzie, M., Schauer, J. J., and Weber, R.: Contribution of particulate brown carbon to light absorption in the rural and urban Southeast US, Atmos. Environ., 136, 95$104,2016$.

Feng, Y., Ramanathan, V., and Kotamarthi, V. R.: Brown carbon: a significant atmospheric absorber of solar radiation?, Atmos. Chem. Phys., 13, 8607-8621, https://doi.org/10.5194/acp13-8607-2013, 2013.

Fuller, G. W., Tremper, A. H., Baker, T. D., Yttri, K. E., and Butterfield, D.: Contribution of wood burning to $\mathrm{PM}_{10}$ in London, Atmos. Environ., 87, 87-94, 2014.

Gyawali, M., Arnott, W. P., Lewis, K., and Moosmüller, H.: In situ aerosol optics in Reno, NV, USA during and after the summer 2008 California wildfires and the influence of absorbing and nonabsorbing organic coatings on spectral light absorption, Atmos. Chem. Phys., 9, 8007-8015, https://doi.org/10.5194/acp-9-80072009, 2009.

Harrison, R. M., Beddows, D. C., Jones, A. M., Calvo, A., Alves, C., and Pio, C.: An evaluation of some issues regarding the use of aethalometers to measure woodsmoke concentrations, Atmos. Environ., 80, 540-548, 2013.

Healy, R., Sofowote, U., Su, Y., Debosz, J., Noble, M., Jeong, C.-H., Wang, J., Hilker, N., Evans, G., and Doerksen, G.: Ambient measurements and source apportionment of fossil fuel and biomass burning black carbon in Ontario, Atmos. Environ., 161, 34-47, 2017.

Helin, A., Niemi, J., Virkkula, A., Pirjola, L., Teinilä, K., Backman, J., Aurela, M., Saarikoski, S., Rönkkö, T., Asmi, E., and Timonen, H.: Characteristics and source apportionment of black carbon in the Helsinki metropolitan area, Finland, Atmos. Environ., 190, 87-98, https://doi.org/10.1016/j.atmosenv.2018.07.022, 2018.

Herich, H., Hueglin, C., and Buchmann, B.: A 2.5 year's source apportionment study of black carbon from wood burning and fossil fuel combustion at urban and rural sites in Switzerland, Atmos. Meas. Tech., 4, 1409-1420, https://doi.org/10.5194/amt-4-14092011, 2011.

Kirchstetter, T. W. and Thatcher, T. L.: Contribution of organic carbon to wood smoke particulate matter absorption of solar radiation, Atmos. Chem. Phys., 12, 6067-6072, https://doi.org/10.5194/acp-12-6067-2012, 2012.
Kirchstetter, T. W., Novakov, T., and Hobbs, P. V.: Evidence that the spectral dependence of light absorption by aerosols is affected by organic carbon, J. Geophys. Res., 109, D21208, https://doi.org/10.1029/2004JD004999, 2004.

Kondo, Y., Sahu, L., Moteki, N., Khan, F., Takegawa, N., Liu, X., Koike, M., and Miyakawa, T.: Consistency and traceability of black carbon measurements made by laser-induced incandescence, thermal-optical transmittance, and filter-based photoabsorption techniques, Aerosol Sci. Technol., 45, 295-312, https://doi.org/10.1080/02786826.2010.533215, 2011.

Lack, D. A. and Cappa, C. D.: Impact of brown and clear carbon on light absorption enhancement, single scatter albedo and absorption wavelength dependence of black carbon, Atmos. Chem. Phys., 10, 4207-4220, https://doi.org/10.5194/acp10-4207-2010, 2010.

Lack, D. A. and Langridge, J. M.: On the attribution of black and brown carbon light absorption using the Ångström exponent, Atmos. Chem. Phys., 13, 10535-10543, https://doi.org/10.5194/acp-13-10535-2013, 2013.

Lack, D. A., Langridge, J. M., Bahreini, R., Cappa, C. D., Middlebrook, A. M., and Schwarz, J. P.: Brown carbon and internal mixing in biomass burning particles, P. Natl. Acad. Sci. USA, 109, 14802-14807, 2012.

Laskin, A., Laskin, J., and Nizkorodov, S. A.: Chemistry of Atmospheric Brown Carbon, Chem. Rev., 115, 4335-4382, https://doi.org/10.1021/cr5006167, 2015.

Liu, C., Chung, C. E., Yin, Y., and Schnaiter, M.: The absorption Ångström exponent of black carbon: from numerical aspects, Atmos. Chem. Phys., 18, 6259-6273, https://doi.org/10.5194/acp18-6259-2018, 2018.

Moosmüller, H., Chakrabarty, R. K., Ehlers, K. M., and Arnott, W. P.: Absorption Ångström coefficient, brown carbon, and aerosols: basic concepts, bulk matter, and spherical particles, Atmos. Chem. Phys., 11, 1217-1225, https://doi.org/10.5194/acp11-1217-2011, 2011.

Moteki, N., Kondo, Y., Miyazaki, Y., Takegawa, N., Komazaki, Y., Kurata, G., Shirai, T., Blake, D. R., Miyakawa, T., and Koike, M.: Evolution of mixing state of black carbon particles: Aircraft measurements over the western Pacific in March 2004, Geophys. Res. Lett., 34, L11803, https://doi.org/10.1029/2006GL028943, 2007.

Russell, P. B., Bergstrom, R. W., Shinozuka, Y., Clarke, A. D., DeCarlo, P. F., Jimenez, J. L., Livingston, J. M., Redemann, J., Dubovik, O., and Strawa, A.: Absorption Angstrom Exponent in AERONET and related data as an indicator of aerosol composition, Atmos. Chem. Phys., 10, 1155-1169, https://doi.org/10.5194/acp-10-1155-2010, 2010.

Saleh, R., Hennigan, C. J., McMeeking, G. R., Chuang, W. K., Robinson, E. S., Coe, H., Donahue, N. M., and Robinson, A. L.: Absorptivity of brown carbon in fresh and photo-chemically aged biomass-burning emissions, Atmos. Chem. Phys., 13, 76837693, https://doi.org/10.5194/acp-13-7683-2013, 2013.

Sandradewi, J., Prevot, A. S. H., Szidat, S., Perron, N., Alfarra, M. R., Lanz, V. A., Weingartner, E., and Baltensperger, U.: Using aerosol light absorption measurements for the quantitative determination of wood burning and traffic emission contributions to particulate matter, Environ. Sci. Technol., 42, 3316-3323, 2008a.

Sandradewi, J., Prevot, A. S. H., Weingartner, E., Schmidhauser, R., Gysel, M., and Baltensperger, U.: A study of wood burning 
and traffic aerosols in an Alpine valley using a multi-wavelength Aethalometer, Atmos. Environ., 42, 101-112, 2008 b.

Schuster, G. L., Dubovik, O., Arola, A., Eck, T. F., and Holben, B. N.: Remote sensing of soot carbon - Part 2: Understanding the absorption Ångström exponent, Atmos. Chem. Phys., 16, 15871602, https://doi.org/10.5194/acp-16-1587-2016, 2016.

Schwarz, J. P., Gao, R. S., Spackman, J. R., Watts, L. A., Thomson, D. S., Fahey, D. W., Ryerson, T. B., Peischl, J., Holloway, J. S., Trainer, M., Frost, G. J., Baynard, T., Lack, D. A., de Gouw, J. A., Warneke, C., and Del Negro, L. A.: Measurement of the mixing state, mass, and optical size of individual black carbon particles in urban and biomass burning emissions, Geophys. Res. Lett., 35, L13810, https://doi.org/10.1029/2008GL033968, 2008.

Shen, Y., Virkkula, A., Ding, A., Wang, J., Chi, X., Nie, W., Qi, X., Huang, X., Liu, Q., Zheng, L., Xu, Z., Petäjä, T., Aalto, P. P., Fu, C., and Kulmala, M.: Aerosol optical properties at SORPES in Nanjing, east China, Atmos. Chem. Phys., 18, 5265-5292, https://doi.org/10.5194/acp-18-5265-2018, 2018.

Shiraiwa, M., Kondo, Y., Moteki, N., Takegawa, N., Sahu, L. K., Takami, A., Hatakeyama, S., Yonemura, S., and Blake, D. R.: Radiative impact of mixing state of black carbon aerosol in Asian outflow, J. Geophys. Res., 113, D24210, https://doi.org/10.1029/2008JD010546, 2008.

Valenzuela, A., Olmo, F. J., Lyamani, H., Antón, M., Titos, G., Cazorla, A., and Alados-Arboledas, L.: Aerosol scattering and absorption Angström exponents as indicators of dust and dust-free days over Granada (Spain), Atmos. Res., 154, 1-13, 2015.
Voshchinnikov, N. V. and Mathis, J. S.: Calculating Cross Sections of Composite Interstellar Grains, Astrophys. J., 526, 257-264, https://doi.org/10.1086/307997, 1999 (code available at: http:// www.astro.spbu.ru/staff/ilin2/SOFTWARE/nmie0.html, last access: 21 May 2021).

Wang, X., Heald, C. L., Sedlacek, A. J., de Sá, S. S., Martin, S. T., Alexander, M. L., Watson, T. B., Aiken, A. C., Springston, S. R., and Artaxo, P.: Deriving brown carbon from multiwavelength absorption measurements: method and application to AERONET and Aethalometer observations, Atmos. Chem. Phys., 16, 12733 12752, https://doi.org/10.5194/acp-16-12733-2016, 2016.

Wu, Z. P. and Wang, Y. P.: Electromagnetic scattering for multilayered spheres: recursive algorithms, Radio Science, 26, 13931401, 1991.

Zhang, X., Mao, M., Yin, Y., and Tang, S.: The absorption Ångstrom exponent of black carbon with brown coatings: effects of aerosol microphysics and parameterization, Atmos. Chem. Phys., 20, 9701-9711, https://doi.org/10.5194/acp-209701-2020, 2020.

Zotter, P., Herich, H., Gysel, M., El-Haddad, I., Zhang, Y., Močnik, G., Hüglin, C., Baltensperger, U., Szidat, S., and Prévôt, A. S. H.: Evaluation of the absorption Ångström exponents for traffic and wood burning in the Aethalometer-based source apportionment using radiocarbon measurements of ambient aerosol, Atmos. Chem. Phys., 17, 4229-4249, https://doi.org/10.5194/acp17-4229-2017, 2017. 